\title{
Covid-19 Pozitif Gebede Acil Sezaryen Anestezisi Yönetimi: Olgu Sunumu
}

\section{Emergency Caesarean Anesthesia Management in Covid-19 Positive Pregnant: Case Report}

\author{
Bedirhan Günel ${ }^{1}$, Fatih Şahin ${ }^{1}$, Ayça Taş Tuna ${ }^{2}$ \\ ${ }^{1}$ Sakarya Üniversitesi Eğitim ve Araştırma Hastanesi Anesteziyoloji ve Reanimasyon Kliniği, Sakarya \\ ${ }^{2}$ Sakarya Üniversitesi Tip Fakültesi, Anesteziyoloji ve Reanimasyon A.B.D, Sakarya \\ Yazı̧̧ma Adresi / Correspondence: \\ Fatih Şahin \\ Sakarya Üniversitesi Tıp Fakültesi Eğitim ve Araştırma Hastanesi Anesteziyoloji ve Reanimasyon Kliniği 54100 Sakarya-Türkiye \\ T: +905062607219 E-mail: tyflfatih16@hotmail.com \\ Geliş Tarihi / Received : 01.07.2020 Kabul Tarihi / Accepted : 22.09.2020 \\ Orcid: \\ Bedirhan Günel: https://orcid.org/0000-0003-2292-9403 \\ Fatih Şahin: https://orcid.org/0000-0002-8501-0675 \\ Ayça Taş Tuna: https://orcid.org/0000-0001-6764-2647 \\ (Sakarya Tip Dergisi / Sakarya Med J 2020, 10(4):690- 693) DOI: 10.31832/smj.762081
}

$\ddot{O} z$

Cin'in Wuhan kentinde 2019'un sonlarında ciddi akut solunum sendromu-koronavirüs 2 (SARS-CoV-2) olarak adlandırılan virüs ortaya çktı. Bu virüsten olusan COVİD19 'dan etkilenen hastalarla daha çok ilgilenmek için ertelenebilecek diğer birçok sağlık hizmetinin aksine, obstetrik hastalar klinik bir öncelik olmaya devam etmektedir. 41 haftalık COVID-19 pozitif gebe fetal distres ve mekonyum nedeniyle operasyona alındı. Spinal anestezi altında operasyon gerçekleștirildi. Türk anesteziyoloji ve Reanimasyon Derneği ve Amerikan Obstetrik Anestezi ve Perinatoloji Derneği sezaryen operasyonları için öneriler yayınladılar. Operasyon odasında tüm ekibin kișisel koruyucu ekipmanlarını kullanmasını sağlayarak, cerrahi hazırlık așamalarını bașka bir ameliyat odasında gerçekleștirerek, negatif basınçlı ameliyat odası kullanarak, hastaya spinal anestezi uygulayarak ve hastanın cerrahi maske takmasını sağlayarak COVID-19 hastası gebenin anestezisini gerçekleștirdik. Böylelikle bulaş riskini en aza indirmeye çalıștık.

Anahtar COVID-19; Sezaryen; Spinal anestezi; Acil sezaryen

kelimeler

Abstract

In late 2019 in Wuhan, China, the virus called serious acute respiratory syndrome-coronavirus 2(SARS-CoV-2) appeared. Unlike many other healthcare services that can be postponed to deal more with patients affected by this virüs, COVID-19, obstetric patients remain a clinical priority. 41 weeks of COVID-19 positive pregnant was taken into operation due to fetal distress and meconium. The operation was performed under spinal anesthesia. Turkish Anesthesiology and Reanimation Association and American Obstetric and Perinatology Association have pubished recommendations for cesarean for cesarean operations. We performed the anesthesia of pregnant woman with COVID-19 by providing the entire team o use the personal protective equipments in the operation room, applying spinal anesthesia to the patient and wearing the surgical mask. Thus, we tried to minimize the risk of transmission.

Keywords COVID-19; Cesarean; Spinal anesthesia; Emergency cesarean 


\section{GIIRIŞ}

Çin'in Wuhan kentinde 2019'un sonlarında nedeni bilinmeyen bir pnömoni tablosu ortaya çıktı ve sonrasında koronavirüsin etken olduğu tespit edildi. Bu virüse, Uluslararası Taksonomi Komitesi ciddi akut solunum sendromu-koronavirüs 2 (SARS-CoV-2) adını verdi. ${ }^{1}$ SARSCoV-2'nin neden olduğu COVİD-19 hastalığ1 11 Mart 2019 tarihinde Dünya Sağlık Örgütü tarafından pandemi olarak kabul edilmiştir. COVİD-19'dan etkilenen hastalarla daha çok ilgilenmek için ertelenebilecek diğer birçok sağlık hizmetinin aksine, obstetrik hastalar klinik bir öncelik olmaya devam etmektedir. ${ }^{2}$ Hastalar asemptomatik tablodan ağır solunum yetmezliği tablosuna kadar çeşitli şekilde hastalığı geçirebilmektedir. Çinde hastalanan 147 gebeden \%8'inin ciddi solunum yetmezliği bulunurken $\% 1$ 'inin ise mekanik ventilasyon ihtiyacı geliştiğini bildirilmiştir. ${ }^{3}$ Türk Anesteziyoloji ve Reanimasyon Derneği COVİD-19 ile ilişkili Obstetrik Anestezi Uygulamasında Geçici Öneriler başlıklı bir geçici kılavuz yayımlayarak COVİD-19’lu gebede sezaryen anestezisi yönetimi için önerilerde bulunmuştur. ${ }^{4} \mathrm{Biz}$ bu olgu sunumunda COVİD-19 pozitif olan bir gebeye başarılı bir şekilde uyguladığımız sezaryen anestezi yönetimi sunmayı amaçladık.

\section{OLGU SUNUMU}

Yirmi altı yaşında, primipar, 41 haftalık gebede fetal distres ve amniyonda mekonyum gözlenmesi sebebiyle acil sezaryen ameliyatı planlandı. Hasta gebeliğinin 39. haftasında COVİD-19 pozitif yakın akraba teması sonrasında boğaz ağrısı, halsizlik, baş ağrısı ve terleme şikayetleri ile acil servise başvurmuş. Hastadan boğaz sürüntü örneği alınmış ve sonrasında kadın doğum servisine yatışı yapılmış. Sürüntü sonucu pozitif hastaya enoksaparin (Enox, Atabay, Turkey) 6000 IU, hidroksiklorokin (Plaquenil, Sanofi, Turkey) $800 \mathrm{mg}$ yükleme ve $400 \mathrm{mg}$ idame tedavisi başlanmış bu tedavi 5 güne tamamlanmış. 5 günlük COVİD-19 tedavisi tamamlandıktan sonra hastanın nonstres test takiplerinde fetal distres bulguları ve amniyon sıvısında mekonyum gözlenmesi üzerine kadın doğum ekibi tarafından acil sezaryen planlandı. Hastanın preo- peratif anormal laboratuvar tetkikleri beyaz kan hücresi 20.4 K/uL, D-Dimer: 2150 ugFEU/L, Ferritin:22,89 $\mu \mathrm{g} / \mathrm{L}$, LDH:289 U/L idi. Operasyona katılacak tüm ekip gerekli kişisel koruyucu ekipmanlarını (KKE) giyindi. Hasta cerrahi maske takılı bir şekilde negatif basınçlı ameliyat odasına alındı. Standart monitörizasyon yapıldı. Preoperatif oda havasinda SpO2:\%99, kan basinc1 (KB): 137/57 mmHg, kalp atım hızı (KAH): 119 atım/dk olarak ölçüldü. Hastaya spinal anestezi uygulanması planlandı ve uygulanacak prosedür hastaya anlatılarak yazılı onam alındı. Hastaya oturur pozisyonda 27 gauge kalem uçlu spinal iğne ile lomber 3-4 intervertebral aralığından girilerek beyin omurilik sıvısı geldiği görüldükten sonra hiperbarik bupivakain \%0,5 (Buvasin heavy \%0,5, Vem, Turkey) 11 mg ve fentanil (Fentaver, Vem, Turkey) $10 \mu \mathrm{g}$ uyguland. Anestezi başlangıcından $20 \mathrm{dk}$ sonra 3500 gram ağırlığında erkek bebek doğdu. Bebek, yenidoğan ekibi tarafından önceden hazırlıkları yapılan negatif basınca sahip farklı bir ameliyat odasına alındı ve ilk müdahaleleri orada yapıldı. 1. ve 5 . dk apgar skoru sırasiyla 9 ve 10 idi. Bebeğin dogumu sonrasinda oksitosin (Synpitan forte, Deva, Turkey) 20 IÜ, $1000 \mathrm{ml} \% 0,9 \mathrm{NaCl}$ içinde infüze edildi. Operasyon süresince KB: 119/60-137/57 mmHg, KAH: 88-119 atım/dk, SpO2:\%98-99 aralıklarında seyretti. Toplam 1 saat süren operasyon sonunda hasta vitalleri stabil şekilde cerrahi maskesi takılı olarak doğumhaneye transfer edildi. Operasyon sonrası kan ve vital değerleri stabil olan hasta postop 2.gününde taburcu edildi. Bu olgu sunumunun bilimsel ortamda paylaşılması için hastadan onam alındı.

\section{TARTIŞMA}

COVİD-19 pozitif gebede anestezi yönetimine rehberlik sağlamak için Faculty of Intensive Care Medicine, Intensive Care Society, Association of Anaesthetists ve Royal College of Anaesthetists tarafindan bir dizi tavsiye yayınlamıştır. Ayrıca Amerikan Obstetrik Anestezi ve Perinatoloji Derneği (SOAP) tarafından da geçici rehber yayımlanmıştır. $^{5} \mathrm{Bu}$ önerilerde epidural anestezinin genel anesteziye tercih edilmesi, KKE kullanılması, entübasyon yapılacaksa en tecrübeli kişi tarafından videolaringoskop ile gerçek- 
leştirilmesi ve zor hava yolu için supraglottik araçların bulundurulması gerektiğini bildirmişlerdir. ${ }^{6}$ Acil sezaryen ameliyatlarında genel anestezi tercih edilebileceği gibi nöroaksiyal anestezi, entübasyon ve ekstübasyon ile ilişkili aerosolizasyon risklerinden kaçınmak için tercih edilmektedir. Buradaki en önemli konu genel anesteziye geçiş ihtimalinden dolayı KKE’lerin seçimi ve doğru kullanımıdır? Türkiye Anesteziyoloji ve Reanimasyon Derneği obstetrik anestezi yönetimi klavuzunda da acil sezaryen ameliyatlarında nöroaksiyel anestezinin tercih edilmesi ve bu işlemi ortamdaki en tecrübeli kişinin yapması önerilmektedir. ${ }^{4}$ Biz de hastamızda spinal anesteziyi tercih ettik fakat bu öneriler ışı̆̆ında olgumuzda başarısız olma ihtimalini düşünerek genel anestezi uygulanacakmış gibi tüm KKE’ları sağladık. KKE, sağlık çalışanları tarafından korunmak ve hastalar arasında enfeksiyonun yayılmasını önlemeye yardımcı olmak için giyilen özel giysi veya ekipmanlardır. Eldiven, önlük, gözlük veya siperlik ve yüz maskelerini içerir. KKE giymek korumayı garanti etmez ve titiz el hijyeni gibi önlemlerle birlikte kullanılmalıdır. ${ }^{8}$ Biz de COVID-19 olduğunu bildiğimiz hastada ameliyat odasında bulunan tüm çalışanlarda KKE tam olarak operasyonu gerçekleştirdik. Hastadan sağlık çalışanlarına bulaş ihtimalini en aza indirmek için hastaya burnunu kapatacak şekilde cerrahi maske takıldı ve preoperatif servisten çıkışından postoperatif servise gidişine kadar maske çıkarılmadı. Operasyon negatif basınç olan odada gerçekleştirildi ve operasyon hazırlığı başka bir ameliyat odasında gerçekleştirildi. $\mathrm{Bu}$ şekilde operasyona katılan kişilerin odada en az sürede kalması sağlandı.

Operasyon odasında tüm ekibin KKE’larını kullanmasını sağlayarak, cerrahi hazırlık aşamalarını başka bir ameliyat odasında gerçekleştirerek, negatif basınçlı ameliyat odası kullanarak, hastaya spinal anestezi uygulayarak ve hastanın cerrahi maske takmasını sağlayarak COVID-19 hastası gebenin anestezisini gerçekleştirdik. Böylelikle bulaş riskini en aza indirmeye çalıştık. 
Sakarya Tip Dergisi 2010;10(4):690-693

\section{Kaynaklar}

1. Gorbalenya AE, Baker SC, Baric RS, Groot RJD, Drosten C, Gulyaeva AA, et al. Severe acute respiratory syndrome-related coronavirus: The species and its viruses - a statement of the Coronavirus Study Group. bioRxiv. 2020:2020.02.07.937862-2020.02.07.

2. England N. Critical care and anaesthesia service reorganisation 2020 Available from: https://www.england.nhs.uk/coronavirus/wp- content/uploads/sites/52/2020/03/Specialtyguide_Critical-care-and-anaesthesia-service-reorganisation_V1_17-March.pdf. Accessed 4 April, 2020.

3. Report of the WHO-China Joint Mission on Coronavirus Disease 2019 (COVID-19) 2020 Available from: https://www.who.int/docs/default-source/coronaviruse/who-chinajoint-mission-on-covid-19-final-report.pdf. Accessed March 25, 2020.

4. http://tard.org.tr/assets/pdf/Obstetrik_Bilimsel_Kurulun_Covid-19_Onerileri.pdf
5. https://soap.org/education/provider-education/expert-summaries/interim-considerations-for-obstetric-anesthesia-care-related-to-covid19/

6. Faculty of Intensive Care Medicine, Intensive Care Society, Association of Anaesthetists, Royal College of Anaesthetists. Management of pregnant women with known or suspected COVID-19. 16 March 2020. Available from: http://icmanaes $\neg$ thesiacovid-19.org

7. Kinsella SM. A prospective audit of regional anaesthesia failure in 5080 Caesarean sections. Anaesthesia 2008;63:822-32.

8. Zimring CM, Matić Z, Wong Sala MF, Mumma JM, Kraft CS, Casanova LM, et al. Making the invisible visible: Why does design matter for safe doffing of personal protection equipment? Infect Control Hosp Epidemiol 2018;39:1375-7. 